\title{
Listeria monocytogenes infection of a popliteal artery stent graft
}

\author{
Avery S. Walker, Joshua P. Smith, Charles A. Andersen, Leo J. Daab* \\ Vascular Surgery Service, Madigan Army Medical Center, Tacoma, United States
}

Received: June 12, 2015

Accepted: July 15, 2015

Online Published: August 8, 2015

DOI: $10.5430 /$ css.v1n $1 \mathrm{p} 11$

URL: http://dx.doi.org/10.5430/css.v1n1p11

\begin{abstract}
Listeria monocytogenes is a pathogen associated with meningitis in the immunosuppressed patient. The pathogen is usually found in soft cheeses and raw milk. We present a case of an infected popliteal artery stent graft with Listeria monocytogenes. The report focuses on the diagnosis and treatment with surgical explantation and vascular reconstruction.
\end{abstract}

Key Words: Listeria monocytogenes, Popliteal artery, Endograft

\section{INTRODUCTION}

Listeria monocytogenes infection is a well-known entity when presenting in the immunosuppressed, pregnant, neonatal, and elderly populations. However, this infection is uncommon in the vascular literature as it pertains to vascular graft infections. Eight cases of vascular graft infections attributed to Listeria have been reported and, to our knowledge, we are presenting the first case of a Listeria infection involving a popliteal artery stent graft. ${ }^{[1-9]}$

\section{CASE REPORT}

We present a case of a 70-year-old male with bilateral popliteal artery aneurysms. This patient has given his full consent to publish this report. He initially underwent a left sided repair with exclusion and bypass complicated by a Methicillin Resistant Staph Aureus (MRSA) wound infection, graft thrombosis, requiring revision, and toe amputation. After sufficient recovery, it was recommended that he undergo an endovascular approach for the treatment of the right sided popliteal aneurysm in light of the complicated course experi- enced with the left sided repair. The right sided repair was performed using overlapping $10 \mathrm{~mm} \times 15 \mathrm{~cm}$ and $10 \mathrm{~mm}$ $\times 10 \mathrm{~cm}$ Gore Viabahn ${ }^{\circledR}$ stent grafts (W.L. Gore, Flagstaff, AZ, USA) via right femoral artery cutdown and placed under fluoroscopic guidance in the operating room in December of 2012 (see Figure 1) with an uneventful recovery. The patient presented one year later complaining of a fever, generalized weakness and cough productive of yellow sputum; findings consistent with pneumonia. He was admitted and began treatment with broad spectrum intravenous antibiotics consisting of piperacillin/tazobactam, ciprofloxacin, and vancomycin.

Two days after admission the patient complained of focal right-sided posterior knee pain. Subsequent venous duplex ruled out an acute deep vein thrombosis. However, a computed tomography (CT) scan of the right lower extremity demonstrated subcutaneous, myofascial, and perivascular edema adjacent to the distal popliteal endovascular stent graft concerning for infection (see Figure 2). Shortly thereafter, a single aerobic blood culture bottle became positive with growth for Listeria monocytogenes. With findings consistent

\footnotetext{
*Correspondence: Leo J. Daab; Email: leo.j.daab.mil@mail.mil; Address: Vascular Surgery Service, Madigan Army Medical Center, 9040-A Fitzsimmons Avenue, Tacoma, Washington 98431, United States.
} 
with a stent graft infection by CT scan, positive blood culture, and clinical findings, a plan was made for graft explantation and bypass through an extra anatomical, non-infected tissue plane. Exploration proceeded with an anteromedial approach beginning proximally. Proximal and distal control was obtained and a saphenous vein graft was then used to create the bypass at the proximal aspect. Prior to creating the bypass, the vein was tunneled in a superficial plane on the medial aspect of the knee in the subcutaneous tissue using a tunneling device. The anastomosis was created just proximal to the previously placed stent. A similar anastomosis was created in the distal popliteal artery. Following the anastomosis the graft was explanted and all side branches were clipped or tied and distal flow was confirmed at the conclusion. Frank purulence was observed during the explantation and drained adjacent to the stent graft and sent for culture which subsequently returned with no growth. To identify the pathogen, the graft and tissue were sent to the Departments of Laboratory Medicine and Microbiology at the University of Washington Medical Center (Seattle, WA). Total DNA was extracted with a High Pure PCR Template preparation kit (Roche Diagnostics, Mannheim, Germany) following the manufacturer's instructions. The first bacterial 16S gene was amplified with standard $16 \mathrm{~S}$ primers. ${ }^{[10]}$ Results of this test confirmed a graft infection with L. monocytogenes. The patient recovered without incident and has been seen in follow up without complications.

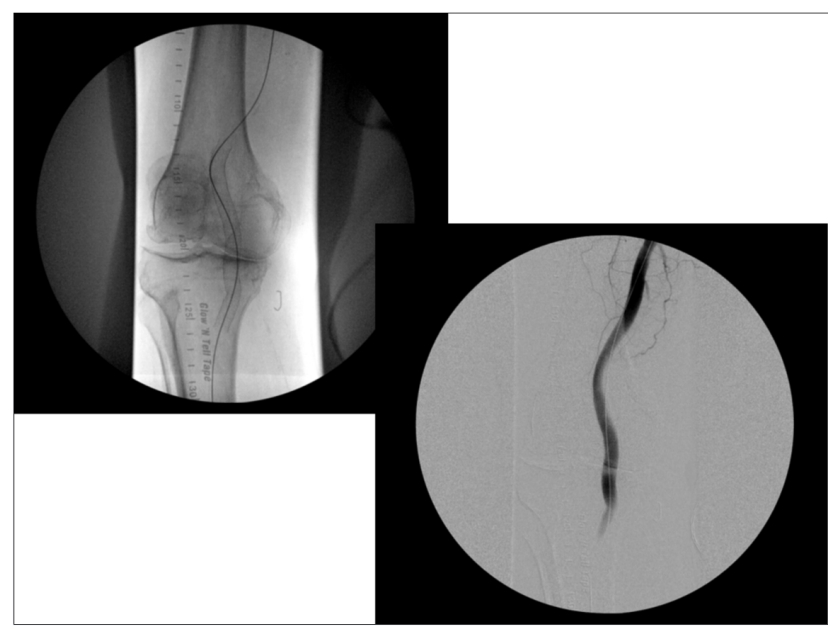

Figure 1. Angiogram of right lower extremity prior to graft explantation

\section{Discussion}

Infections are rare in endovascularly placed stents or stent grafts $(0.6 \%$ to $3 \%) .{ }^{[1]}$ In the setting of an infected graft, mortality ranges from $25 \%-75 \% .{ }^{[2]}$ Expanded polytetrafluoroethylene (ePTFE)-covered stent grafts or polyester-covered 12 stent grafts might be more susceptible to infection than a bare metal stent. ${ }^{[1]}$ The current gold standard of treatment for an infected synthetic graft was employed in this patient with removal of the infected artery and stent, antibiotic therapy, and arterial reconstruction through a non-infected tissue plane. Two reports have demonstrated that in patients with a high perioperative risk, preservation of the endograft was accomplished with prolonged high-dose antimicrobial therapy combined with image-guided percutaneous drainage or surgical debridement, but without graft removal. ${ }^{[3,4]}$ This treatment was discussed, but our patient was deemed appropriate for excision and extra-anatomic bypass. Of note, Saleem et al. reported that conservative treatment for infected vascular endografts was the most important predictor of mortality on multivariate analysis. It was suggested that this strategy should only be taken with those patients who would not tolerate an extensive surgical procedure. ${ }^{[5]}$
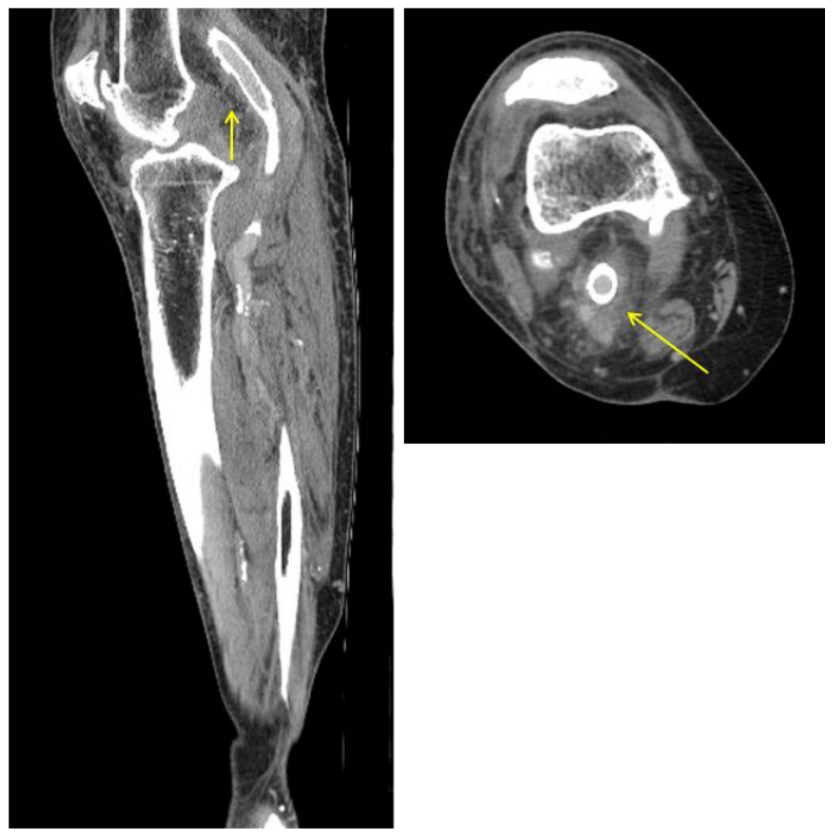

Figure 2. CT scan of the right lower extremity demonstrating the peri-graft inflammatory findings consistent with a graft infection (arrow)

Diagnosing a graft infection can be extremely difficult. Symptoms are often nonspecific. However, the patient described had point tenderness behind his knee. Contrast enhanced CT scan is considered the diagnostic study of choice with a sensitivity of $94 \%$ and a specificity of $85 \% .^{[5]}$ The diagnosis in our patient was made by observing point tenderness at the knee, positive blood cultures, and a CT scan demonstrating perigraft inflammatory changes. This diagnosis was confirmed using molecular genetic techniques directed at the explanted graft itself which identified the strain 
of bacteria. Cultures taken from the infected site did not grow Listeria. However, this is not uncommon as blood cultures are only positive in $21 \%$ of cases and cultures of drain fluid or of the prosthesis itself are positive in only $50 \%$ of cases. ${ }^{[6]}$ In a literature review, we were unable to identify any reports of infected stent grafts in the popliteal artery with Listeria monocytenes. Of the 8 reported cases of graft infections with Listeria, the majority were infected aortic grafts. $^{[1,3,7-9,11,12]}$ An infection of Viabahn ${ }^{\circledR}$ stent grafts is extremely unusual. ${ }^{[1]}$ Listeria monocytogenes is an anaerobic, gram positive bacillus usually found in the soil and fecal flora of mammals. ${ }^{[13]}$ Patients infected with L. monocytogenes are typically immunocompromised, pregnant women, elderly, or neonates. ${ }^{[13]}$ Our patient did not meet any of these conditions. Infection with Listeria can present with three general syndromes: meningo-enchephalitis in non pregnant patients, sepsis, and perinatal listerosis. The patient reported no history of immunocompromise or contact with anyone infected with Listeria, nor had he consumed raw milk or soft cheeses in the previous days. Microbial colonization of a vascular graft may arise from contamination at the time of surgery, direct extension from adjacent infected tissue or viscus, or hematogenous seeding during an episode of bacteremia. In view of the well documented occurrence of cryptic listeremia in otherwise healthy individuals, e.g. during pregnancy, there is little doubt that this is the most probable origin of the graft infection in our patient. Up to $50 \%$ of all persons carry L. monocytogenes in their intestinal tract. $^{[13]}$ Asymptomatic carriage may occasionally lead to transient bacteremia when accompanied with a break in the mucosal barrier. This is generally controlled by host defense mechanisms. Interestingly, Gallagher and colleagues demonstrated that Listeria has been shown to have a high affinity for endovascular epithelium as well artificial epithelium in the realm of infective endocarditis. ${ }^{[14,15]}$

\section{Conclusion}

Vascular stent graft infections can be difficult to diagnose and the treatment can be associated with a high morbidity and mortality rate. Contrast enhanced CT scans are the diagnostic imaging modalities of choice with or without the addition of a tagged WBC scan to confirm an inflammatory process versus benign perigraft fluid collections. The gold standard treatment of explantation and reconstruction with autogenous conduit is associated with the lowest morbidity and mortality. However, a conservative approach of antibiotics alone may be warranted in the high-risk patient. Listeria monocytogenes is a rare bacterium that has been shown to colonize artificial surfaces and should remain in the differential when treating vascular graft infections.

\section{REFERENCES}

[1] Schneider JR, Patel NH, Hashemi F, et al. Infected Viabahn stent graft in the superficial femoral artery. Eur J Vasc Endovasc Surg. Nov 2011; 42(5): 699-703. PMid: 21889371. http://dx.doi.org/10. 1016/j.ejvs. 2011.08.005

[2] Treitl M, Rademacher A, Becker-Lienau J, et al. Successful antibiotic treatment of severe staphylococcal infection of a long stent graft in the superficial femoral artery with graft preservation in the long term. Cardiovasc Intervent Radiol. Jun 2011; 34(3): 642-646. PMid: 21088841. http://dx.doi.org/10.1007/s00270-010-0040-7

[3] Saleem BR, Berger P, Zeebregts CJ, et al. Periaortic endograft infection due to Listeria monocytogenes treated with graft preservation. J Vasc Surg. Mar 2008; 47(3): 635-637. PMid: 18295117. http://dx.doi.org/10.1016/j.jvs.2007.09.029

[4] Tanner-Steinmann B, Boggian K. Vascular Endograft Infection with Listeria monocytogenes reated with Surgical Debridement but without Graft Removal. Case Rep Med. 2011; 2011: 482815.

[5] Saleem BR, Meerwaldt R, Tielliu IF, et al. Conservative treatment of vascular prosthetic graft infection is associated with high mortality. Am J Surg. Jul 2010; 200(1): 47-52. PMid: 20074700. http://dx.doi.org/10.1016/j. amjsurg. 2009.05.018

[6] Papadoulas SI, Kakkos SK, Kraniotis PA, et al. Listeriosis infection of an abdominal aortic aneurysm in a diabetic patient. $\mathrm{J}$ Glob Infect Dis. Jan 2013; 5(1): 31-33. PMid: 23599616. http: //dx.doi.org/10.4103/0974-777X.107173
[7] Rohde H, Horstkotte MA, Loeper S, et al. Recurrent Listeria monocytogenes aortic graft infection: confirmation of relapse by molecular subtyping. Diagn Microbiol Infect Dis. Jan 2004; 48(1): 63-67. PMid: 14761724. http://dx.doi.org/10.1016/j.diagmicro bio. 2003.08 .003

[8] Heikkinen L, Valtonen M, Lepantalo M, et al. Infrarenal endoluminal bifurcated stent graft infected with Listeria monocytogenes. J Vasc Surg. Mar 1999; 29(3): 554-556. http://dx.doi.org/10.1016 /S0741-5214(99) 70285-5

[9] Van Noyen R, Reybrouck R, Peeters P, et al. Listeria monocytogenes infection of a prosthetic vascular graft. Infection. Mar-Apr 1993; 21(2): 125-126. PMid: 8491522. http://dx.doi.org/10.1007 /BF01710749

[10] Salipante SJ, Sengupta DJ, Rosenthal C, et al. Rapid 16S rRNA Next-Generation Sequencing of Polymicrobial Clinical Samples for Diagnosis of Complex Bacterial Infections. PLoS ONE. 2013; 8(5): e65226. http://dx.doi.org/10.1371/journal.pone. 0065226

[11] Gauto AR, Cone LA, Woodard DR, et al. Arterial infections due to Listeria monocytogenes: report of four cases and review of world literature. Clin Infect Dis. Jan 1992; 14(1): 23-28. PMid: 1571436. http://dx.doi.org/10.1093/clinids/14.1.23

[12] Zeitlin J, Carvounis CP, Murphy RG, et al. Graft infection and bacteremia with Listeria monocytogenes in a patient receiving hemodialysis. Arch Intern Med. Nov 1982; 142(12): 2191-2192. PMid: 
7138165. http://dx.doi.org/10.1001/archinte.1982.003 40250157024

[13] Kluge RM. Listeriosis-problems and therapeutic options. J Antimicrob Chemother. Jun 1990; 25(6): 887-890. PMid: 2115036. http://dx.doi.org/10.1093/jac/25.6.887

[14] Gallagher PG, Watanakunakorn C. Listeria monocytogenes endo- carditis: a review of the literature 1950-1986. Scand J Infect Dis. 1988; 20(4): 359-368. http://dx.doi.org/10.3109/0036554 8809032469

[15] Carvajal A, Frederiksen W. Fatal endocarditis due to Listeria monocytogenes. Rev Infect Dis. May-Jun 1988; 10(3): 616-623. PMid: 3293164. http://dx.doi.org/10.1093/clinids/10.3.616 